Supplement of Nat. Hazards Earth Syst. Sci., 19, 1215-1234, 2019

https://doi.org/10.5194/nhess-19-1215-2019-supplement

(C) Author(s) 2019. This work is distributed under

the Creative Commons Attribution 4.0 License.

(c) (1)

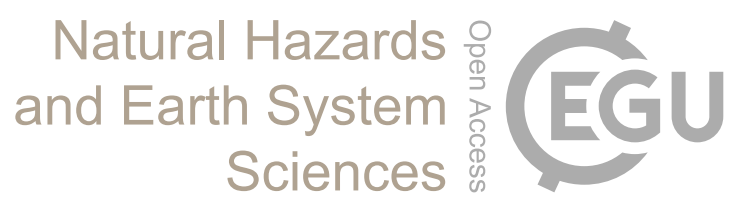

Supplement of

\title{
The impact of drought on the productivity of two rainfed crops in Spain
}

Marina Peña et al.

Correspondence to: Marina Peña-Gallardo (marinapgallardo@ipe.csic.es)

The copyright of individual parts of the supplement might differ from the CC BY 4.0 License. 
Supplementary Table 1. Relationship between provincial and agricultural district data, aggregated at the provincial scale, for wheat cultivation for the common period 1993-2014.

\begin{tabular}{|c|c|c|c|c|c|}
\hline Codes & Provinces & $\mathbf{r}$ & Codes & Provinces & $\mathbf{r}$ \\
\hline 1 & Álava & 0.16 & 23 & Jaén & $0.38^{*}$ \\
\hline 2 & Albacete & $0.41^{*}$ & 24 & León & $0.69^{*}$ \\
\hline 3 & Alicante & 0.1 & 25 & Lleida & $0.52^{*}$ \\
\hline 4 & Almería & $0.47^{*}$ & 26 & La Rioja & $0.35^{*}$ \\
\hline 5 & Ávila & $0.77^{*}$ & 28 & Madrid & $0.81^{*}$ \\
\hline 6 & Badajoz & $0.49^{*}$ & 29 & Málaga & 0.11 \\
\hline 7 & Islas Baleares & -0.22 & 30 & Murcia & 0.13 \\
\hline 8 & Barcelona & $0.69^{*}$ & 31 & Navarra & -0.25 \\
\hline 9 & Burgos & $0.82^{*}$ & 32 & Ourense & $0.37^{*}$ \\
\hline 10 & Cáceres & $0.34^{*}$ & 33 & Asturias & -0.16 \\
\hline 11 & Cádiz & $0.32^{*}$ & 34 & Palencia & $0.73^{*}$ \\
\hline 12 & Castellón & -0.19 & 37 & Salamanca & $0.87^{*}$ \\
\hline 13 & Ciudad Real & $0.43^{*}$ & 40 & Segovia & $0.94^{*}$ \\
\hline 14 & Córdoba & $0.46^{*}$ & 41 & Sevilla & 0.25 \\
\hline 15 & A Coruña & 0.1 & 42 & Soria & $0.89^{*}$ \\
\hline 16 & Cuenca & $0.86^{*}$ & 43 & Tarragona & $0.54^{*}$ \\
\hline 17 & Girona & 0.1 & 44 & Teruel & $0.83^{*}$ \\
\hline 18 & Granada & 0.3 & 45 & Toledo & $0.48^{*}$ \\
\hline 19 & Guadalajara & $0.87^{*}$ & 46 & Valencia & 0.2 \\
\hline 21 & Huelva & 0.29 & 47 & Valladolid & $0.92^{*}$ \\
\hline
\end{tabular}




\begin{tabular}{|l|l|ll|l|}
22 Huesca & $0.4^{*}$ & 49 & Zamora & $0.75^{\star}$ \\
& & 50 & Zaragoza & $0.51^{*}$ \\
\hline
\end{tabular}

${ }^{*}$ ) correlations are significant at $p<0.05$

Supplementary Table 2. Relationship between provincial and agricultural district data, aggregated at provincial scale, for barley cultivation for the common period 1993-2014.

\begin{tabular}{|c|c|c|}
\hline $\begin{array}{c}\text { Code } \\
s\end{array}$ & Provinces & $\mathbf{r}$ \\
\hline 1 & Álava & 0.11 \\
\hline 2 & Albacete & 0.2 \\
\hline 10 & Cáceres & $0.48^{*}$ \\
\hline 11 & Cádiz & $0.32^{*}$ \\
\hline 12 & Castellón & -0.14 \\
\hline 13 & $\begin{array}{l}\text { Ciudad } \\
\text { Real }\end{array}$ & 0.28 \\
\hline 14 & Córdoba & $0.54^{*}$ \\
\hline 15 & A Coruña & -0.09 \\
\hline 16 & Cuenca & $0.88^{*}$ \\
\hline 17 & Girona & 0.08 \\
\hline 18 & Granada & $0.51^{*}$ \\
\hline 19 & $\begin{array}{l}\text { Guadalajar } \\
\text { a }\end{array}$ & $0.86^{*}$ \\
\hline 22 & Huelva & $0.57^{*}$ \\
\hline 26 & La Rioja & $0.76^{\star}$ \\
\hline 31 & Navarra & 0.01 \\
\hline 41 & Sevilla & $0.5^{-}$ \\
\hline 43 & Tarragona & $0.88^{*}$ \\
\hline
\end{tabular}

$\left(^{*}\right)$ correlations are significant at $p<0.05$ 
a) Agricultural district - Wheat

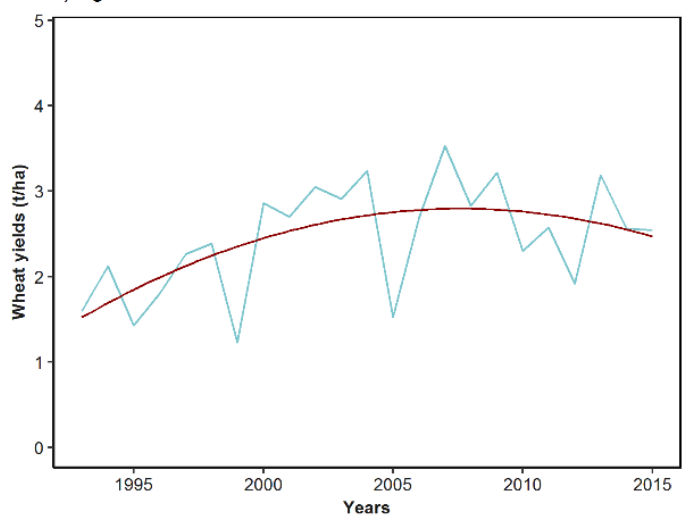

b ) Agricultural district - Barley

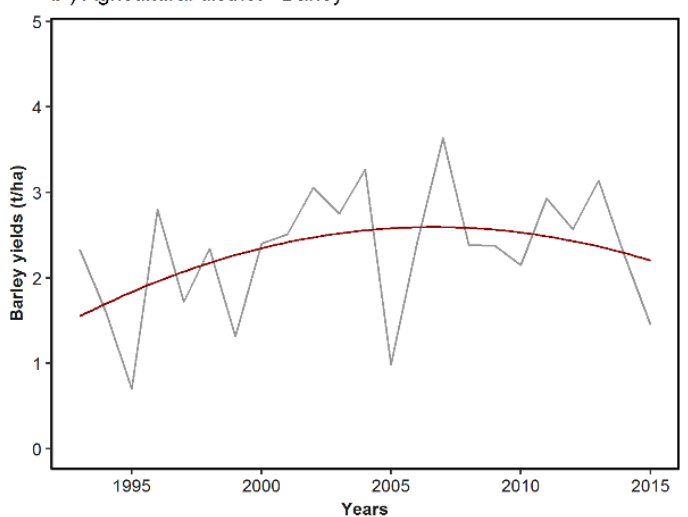

c) Agricultural district - SYRS

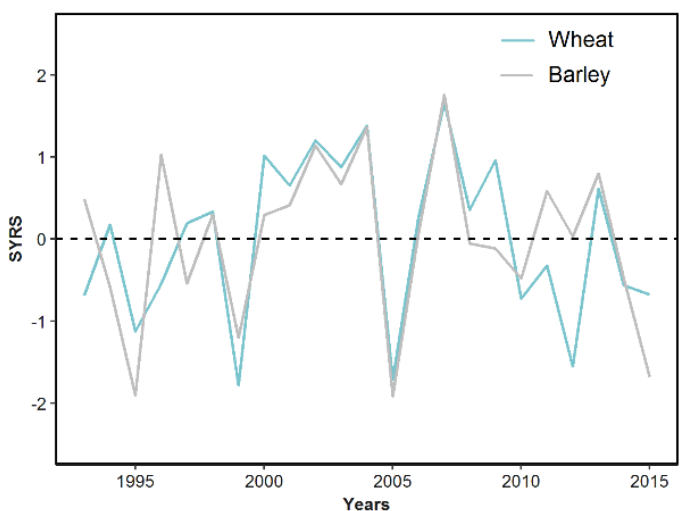

d) Provincial - Wheat

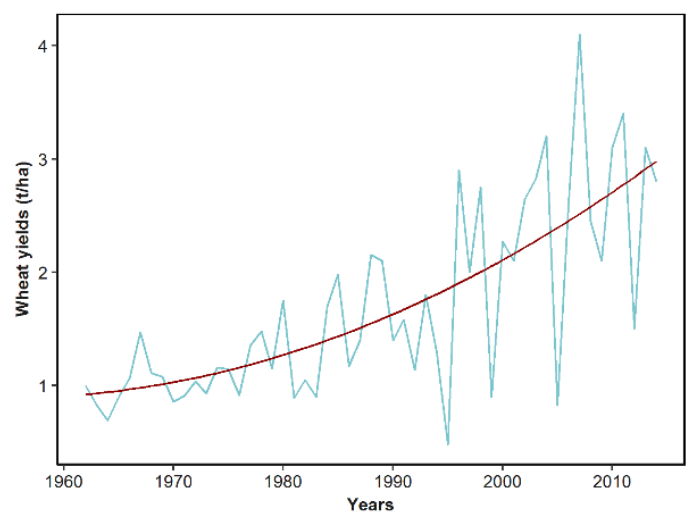

e) Provincial - Barley

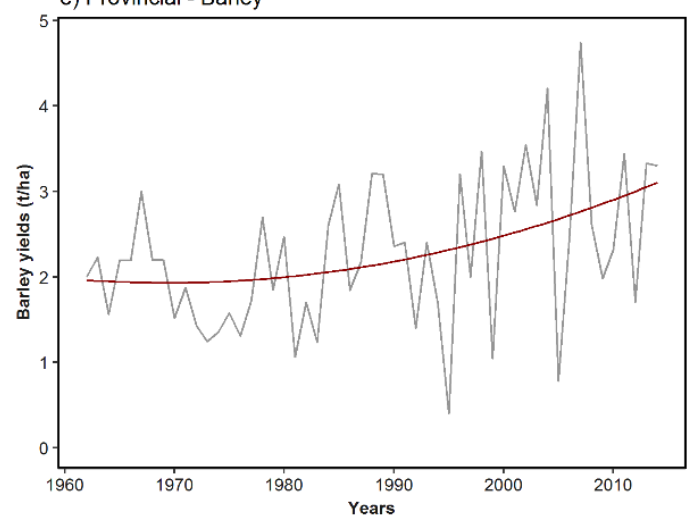

f) Provincial - SYRS

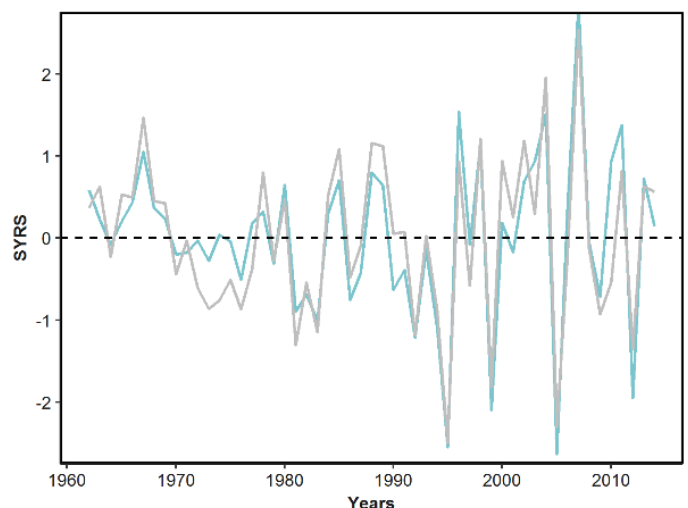

Supplementary Fig. 1. Example of temporal trends of provincial and agricultural district yields of wheat $(a, d)$ and barley $(b, e)$ in the province of Cáceres and the district Navalmoral de la Mata (Cáceres) and the temporal evolution of the SYRS at both scales (c, f) for the available period of time in each case. Red line represents the fitting of a quadratic function. Dashed black line represents the threshold 0 -value. 


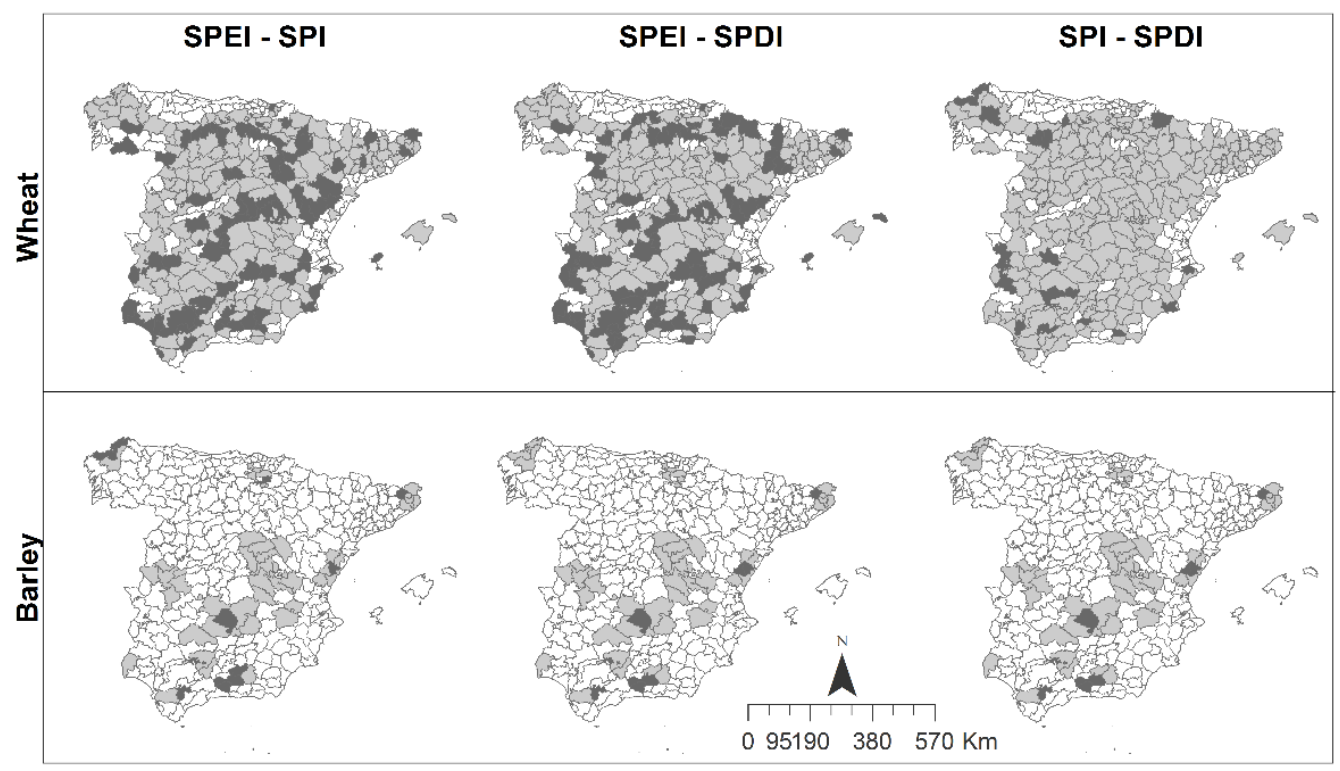

Supplementary Fig. 2. Spatial distribution of regions where significant differences (dark grey) and non significant differences (light grey) were found in the t-tests.
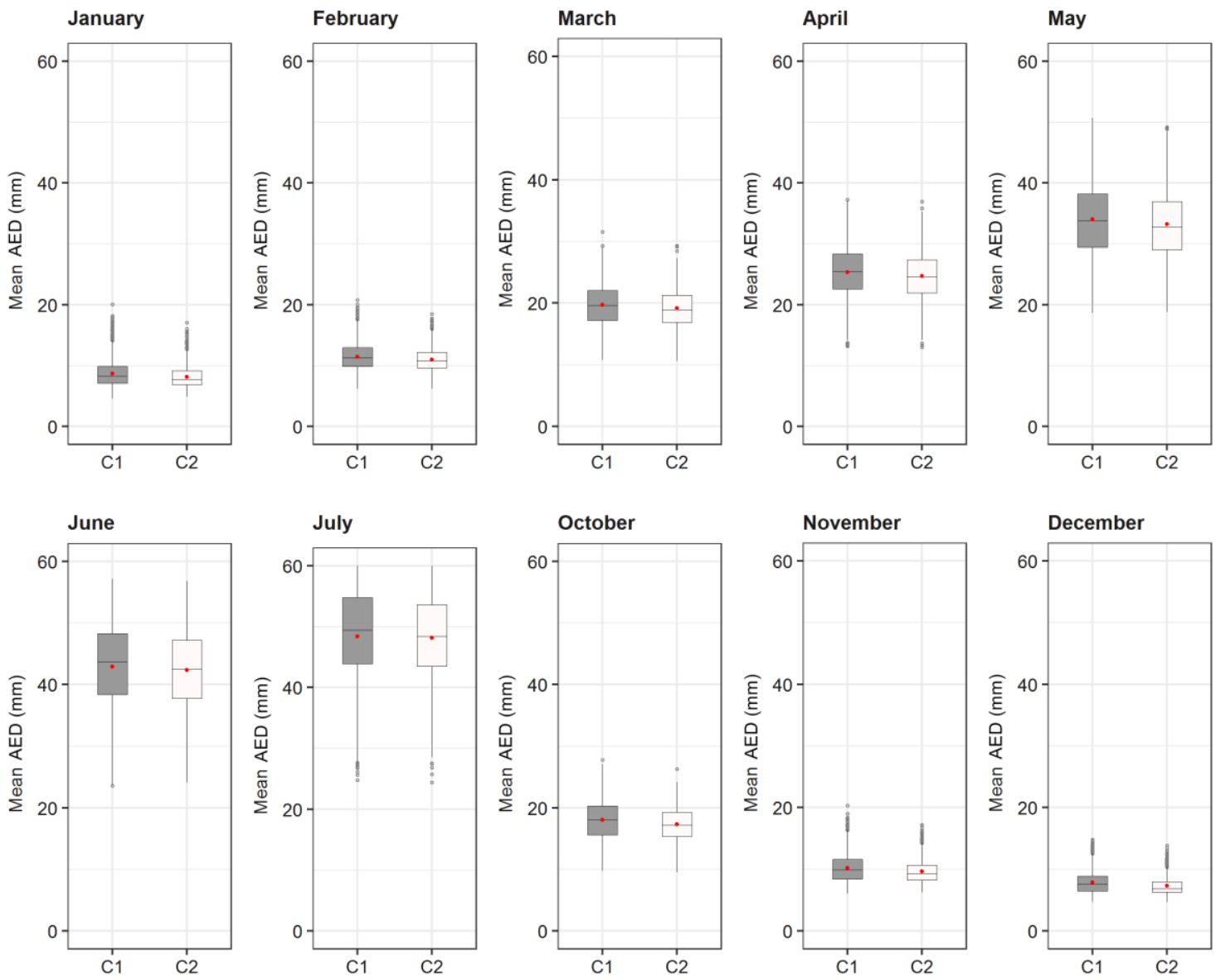

Supplementary Fig. 3. Monthly mean AED conditions in the agricultural districts where wheat was cultivated, classified into principal components ( $\mathrm{C} 1$ and $\mathrm{C} 2$ ) for the period 1993-2015. The red dot shows the mean, and the black line shows the median. 

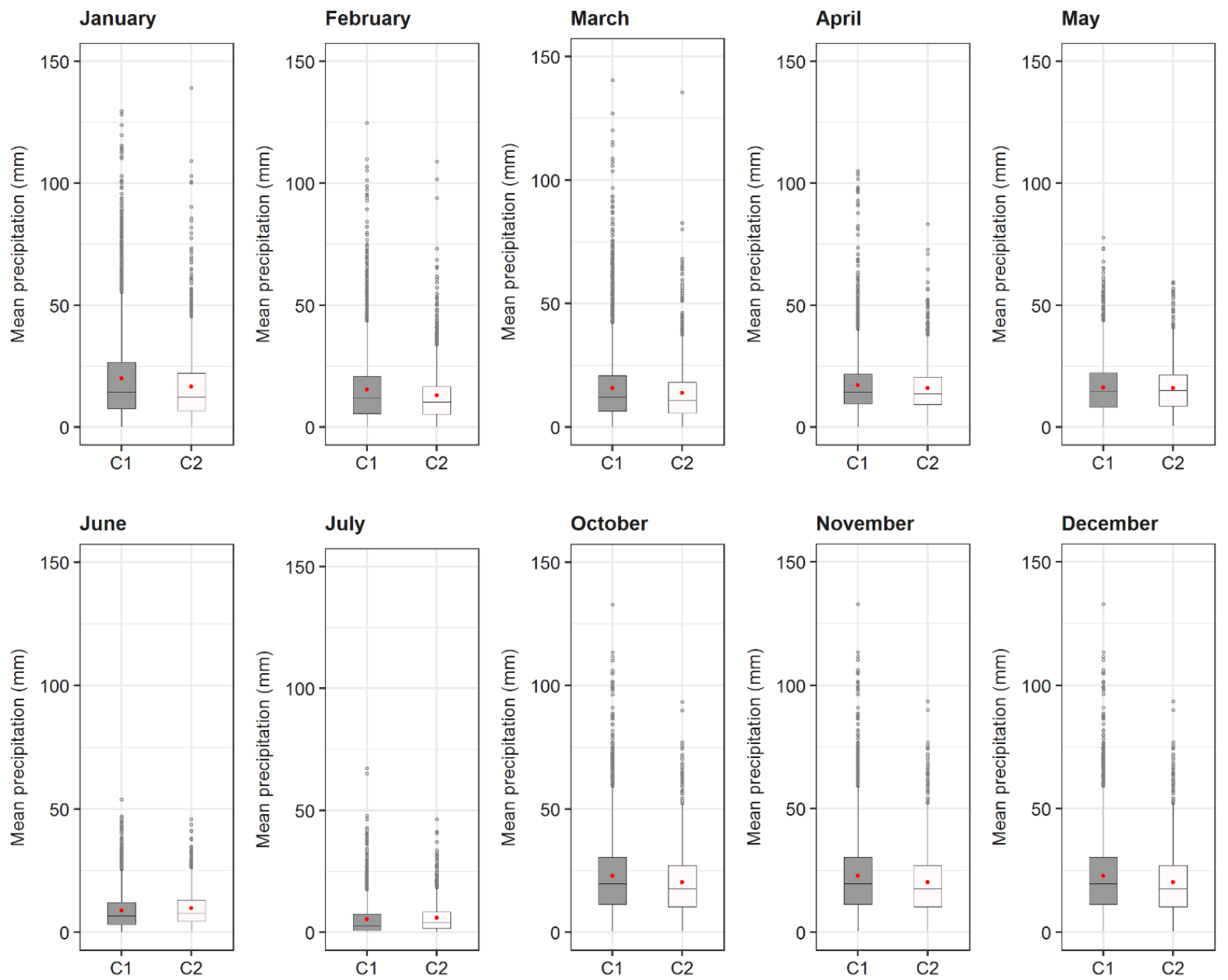

Supplementary Fig. 4. As for Supplementary Fig. 3, but for the monthly mean precipitation. 

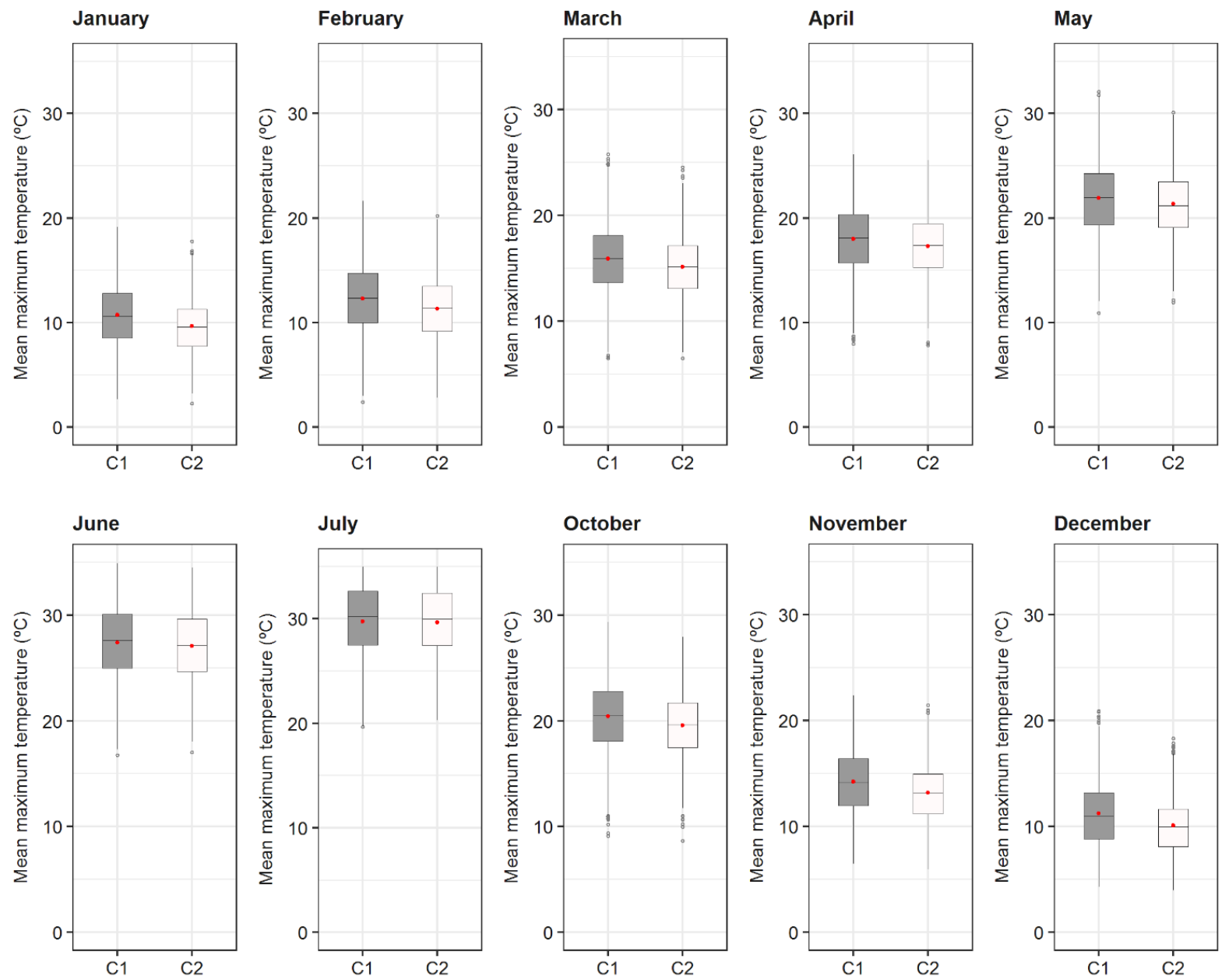

Supplementary Fig. 5. As for Supplementary Fig. 3, but for the monthly mean maximum temperature. 

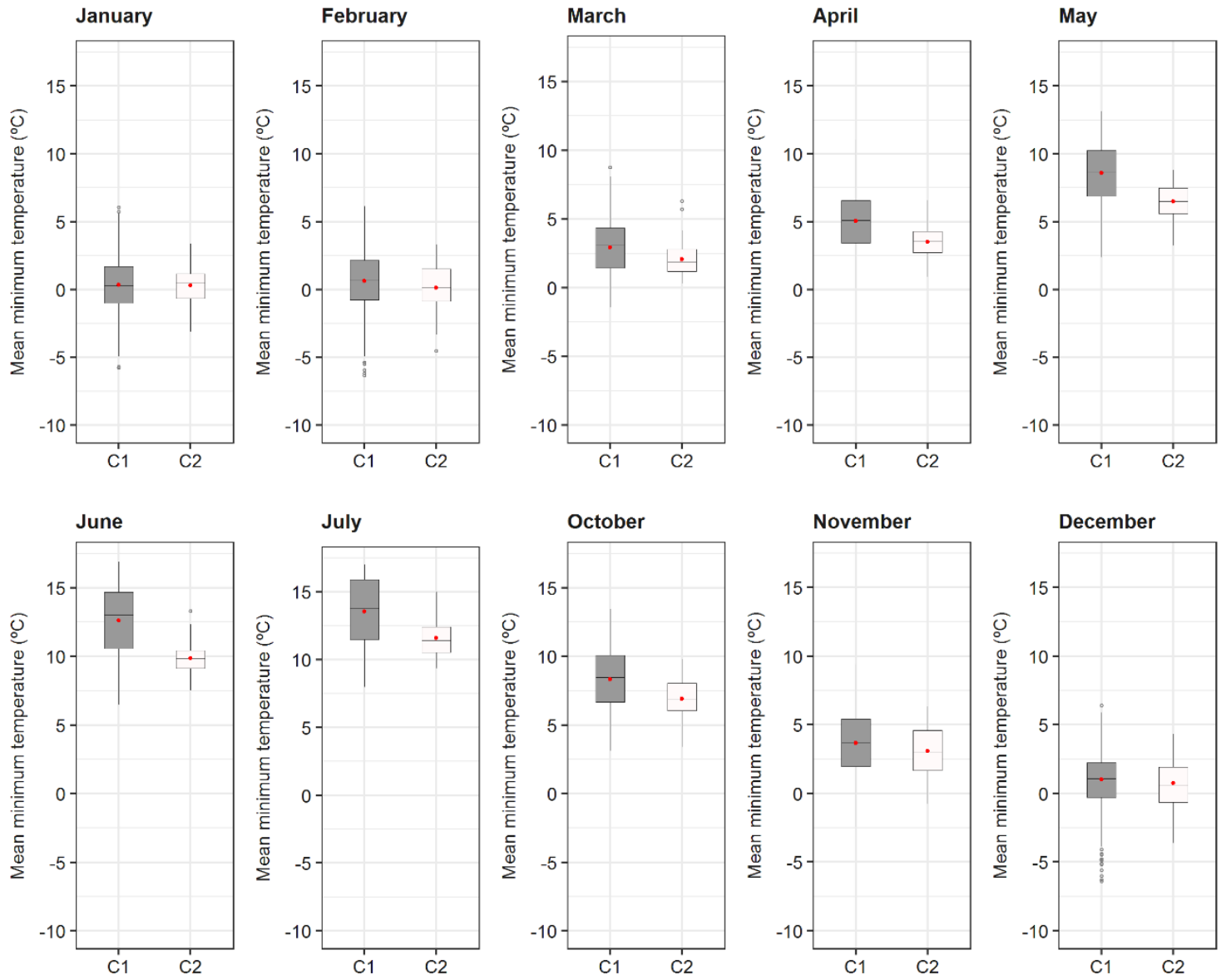

Supplementary Fig. 6. As for Supplementary Fig. 3, but for the monthly mean minimum temperature. 

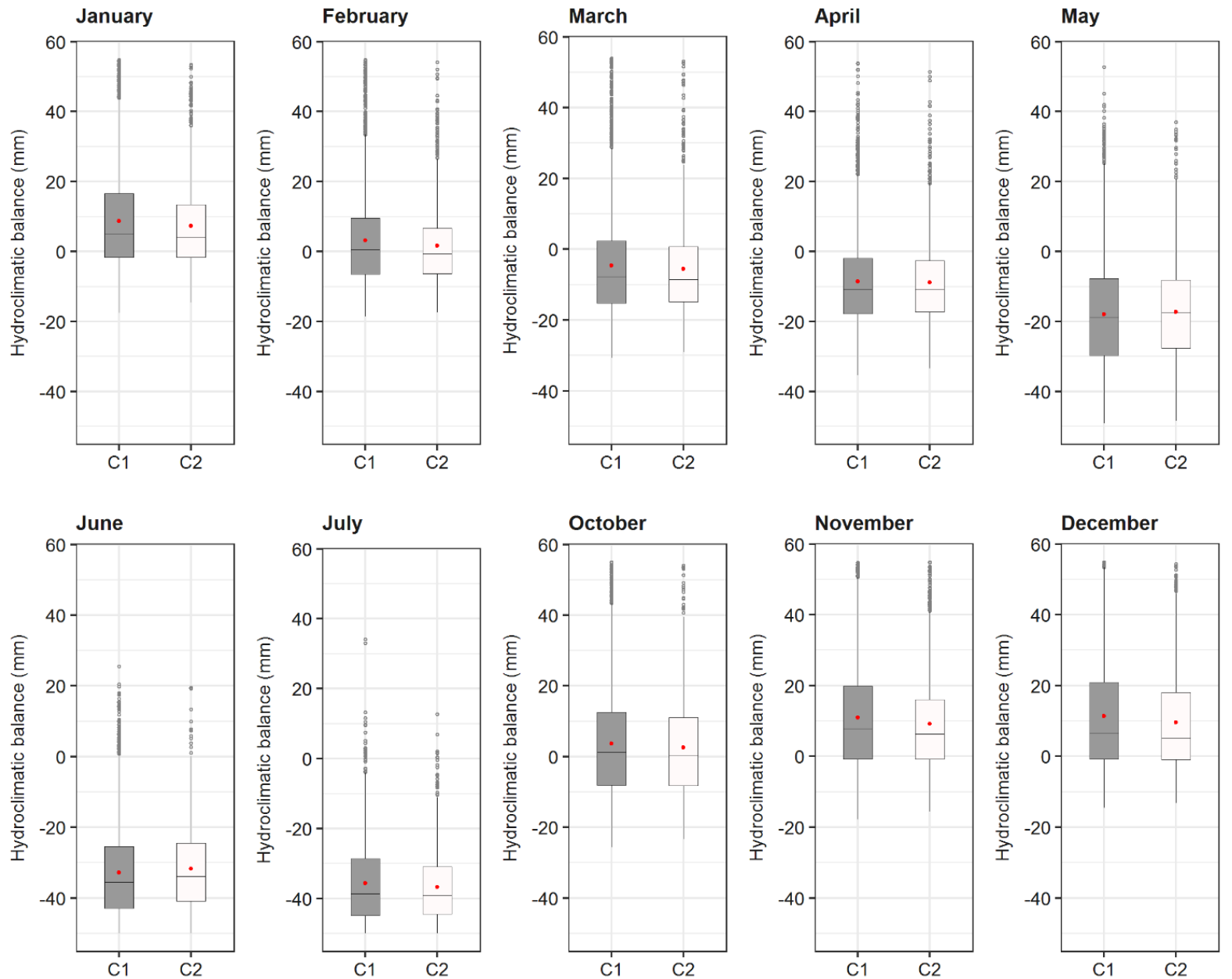

Supplementary Fig. 7. As for Supplementary Fig. 3, but for the monthly mean hydroclimate balance. 

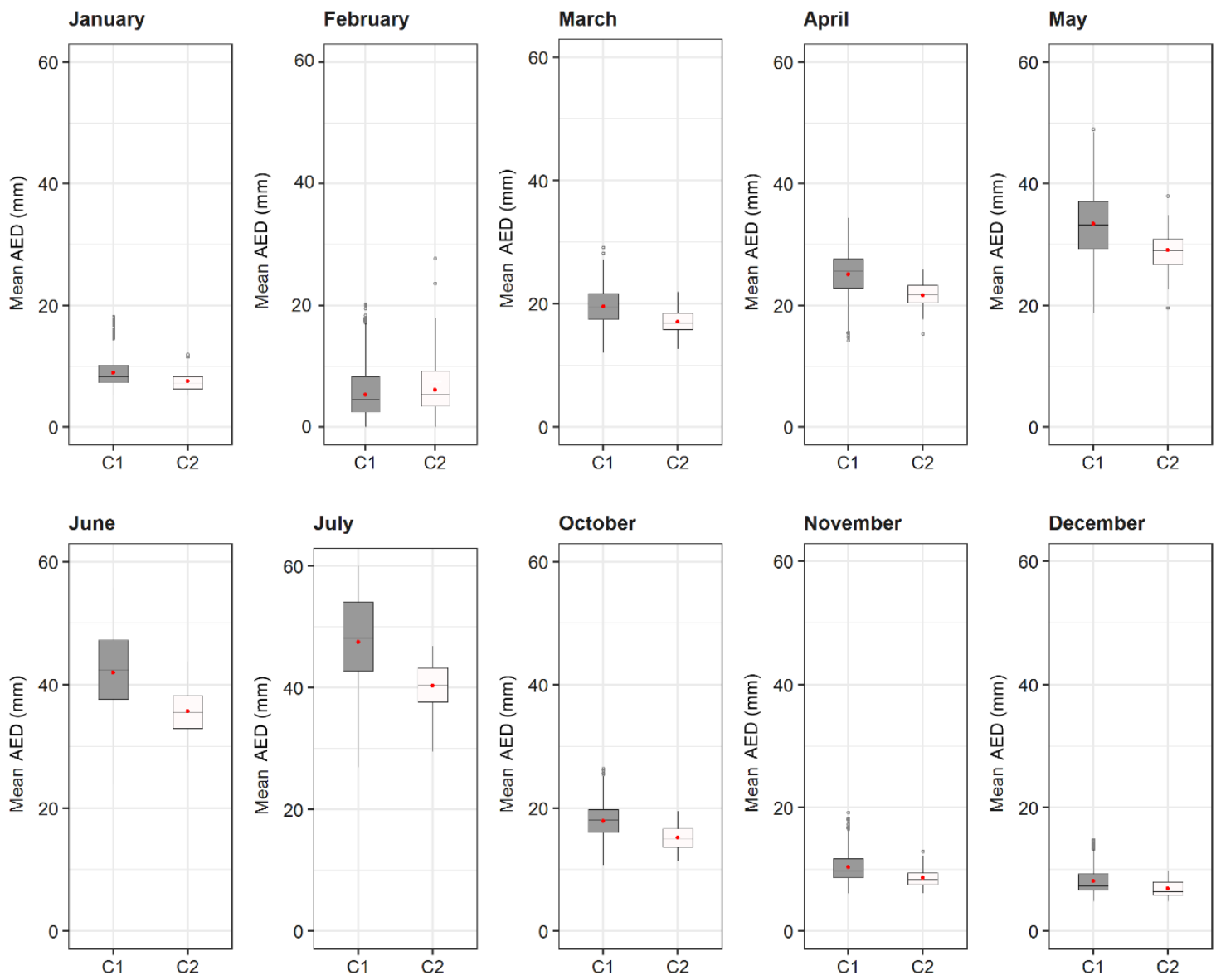

Supplementary Fig. 8. Monthly mean AED conditions in the agricultural districts where barley was cultivated, classified into principal components ( $\mathrm{C} 1$ and $\mathrm{C} 2$ ) for the period 1993-2015. The red dot show the mean, and black line shows the median. 

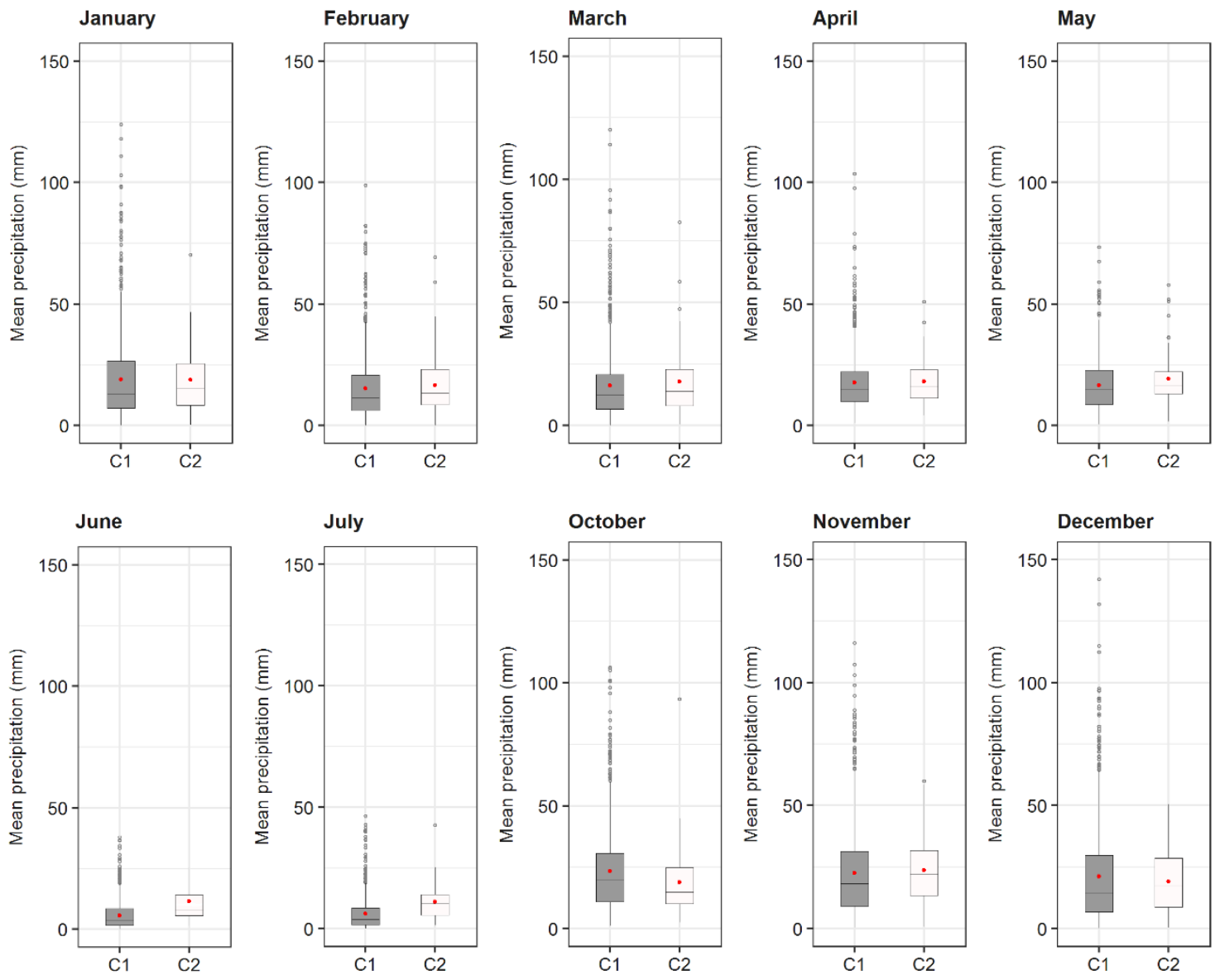

Supplementary Fig. 9. As for Supplementary Fig. 8, but for the monthly mean precipitation. 

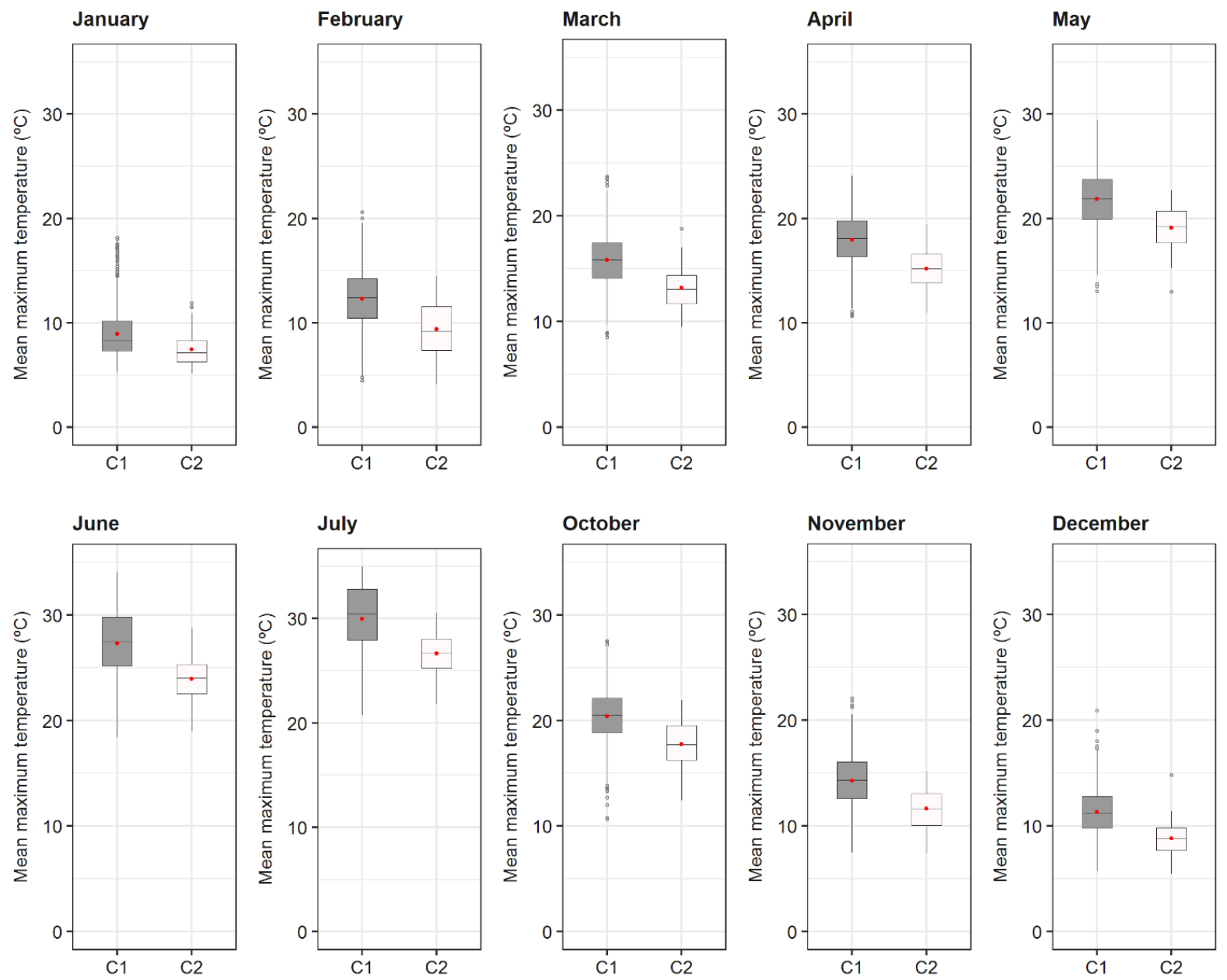

Supplementary Fig. 10. As for Supplementary Fig. 8, but for the monthly mean maximum temperature. 

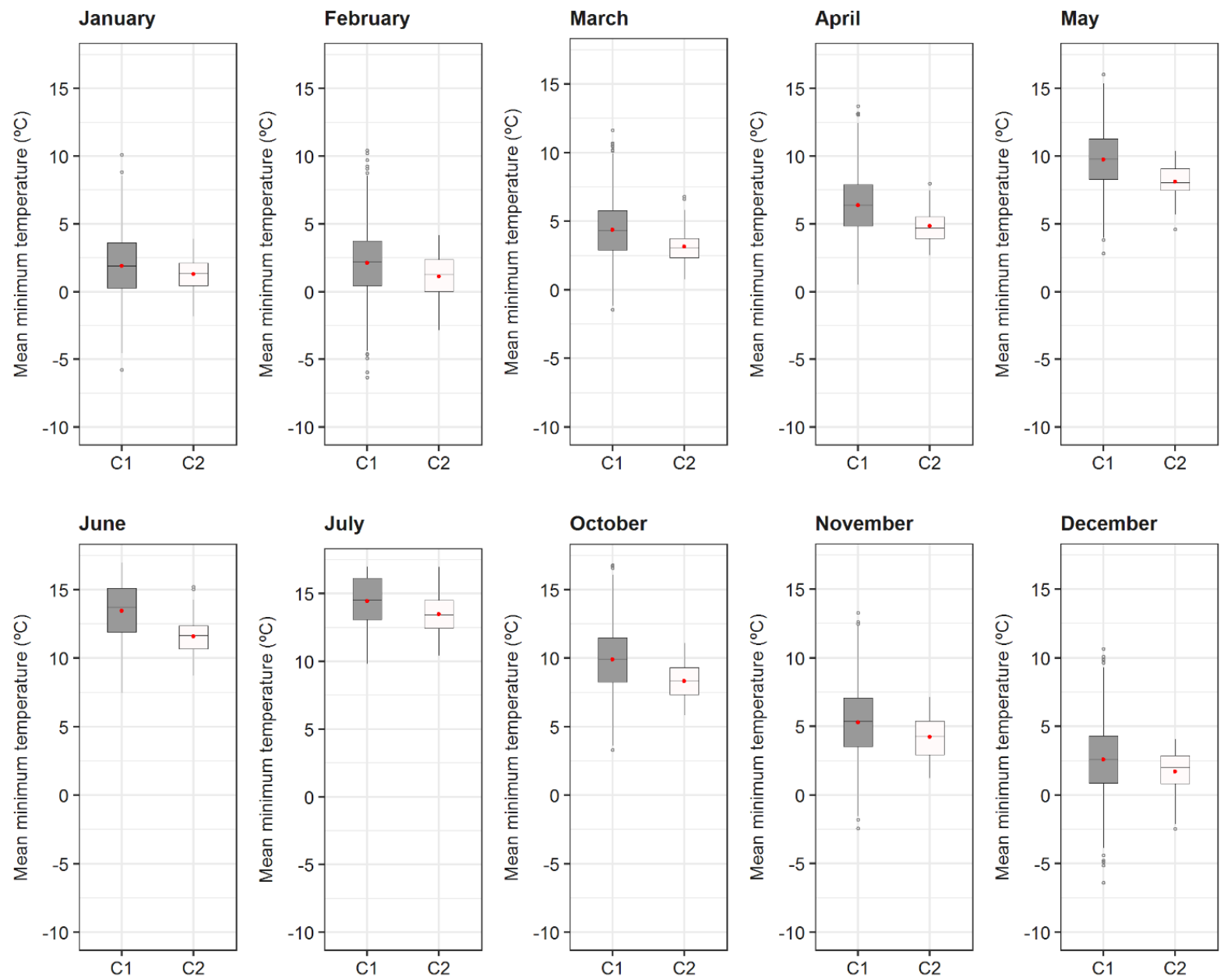

Supplementary Fig. 11. As for Supplementary Fig. 8, but for the monthly mean minimum temperature. 

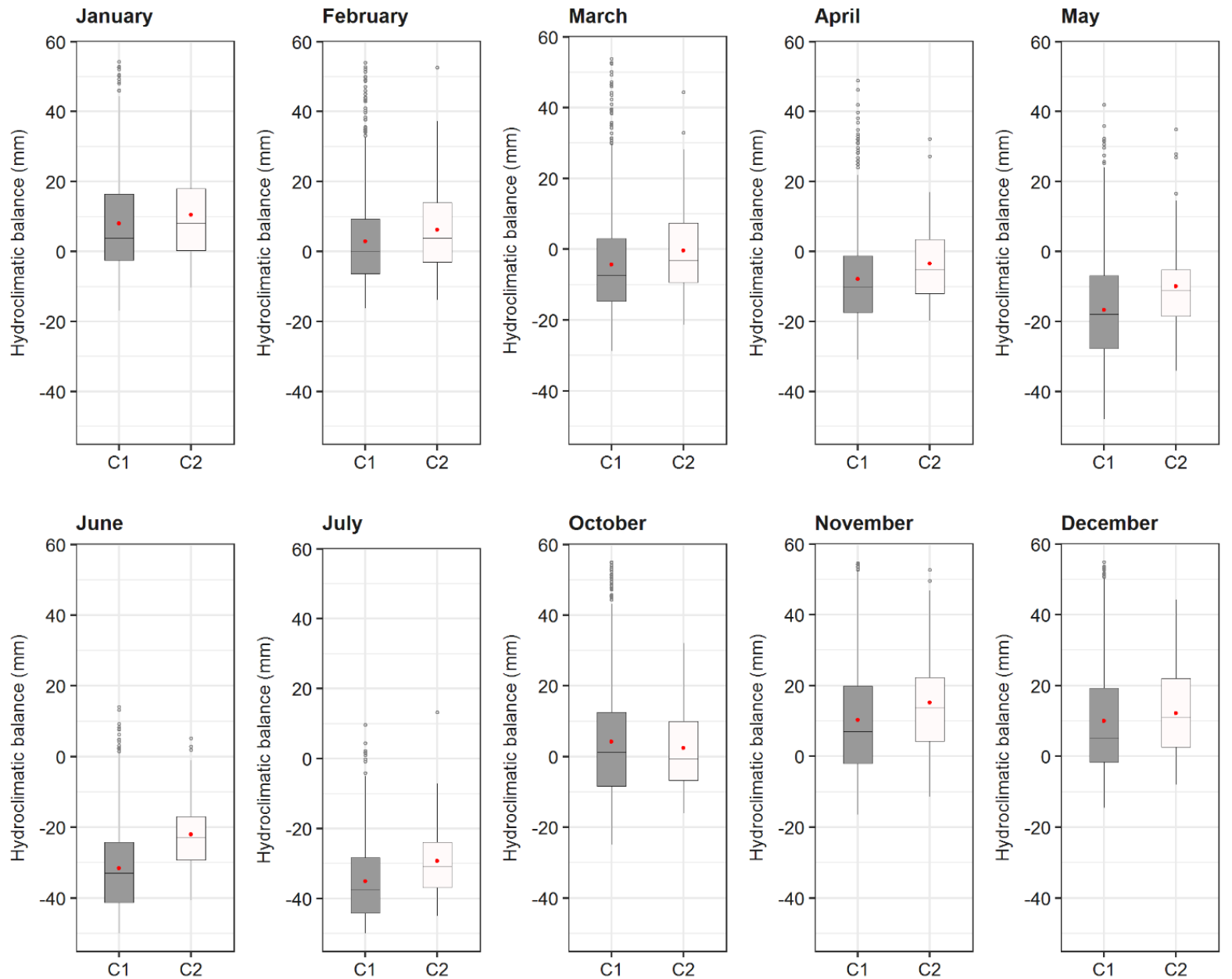

Supplementary Fig. 12. As for Supplementary Fig. 8, but for the monthly mean hydroclimate balance. 